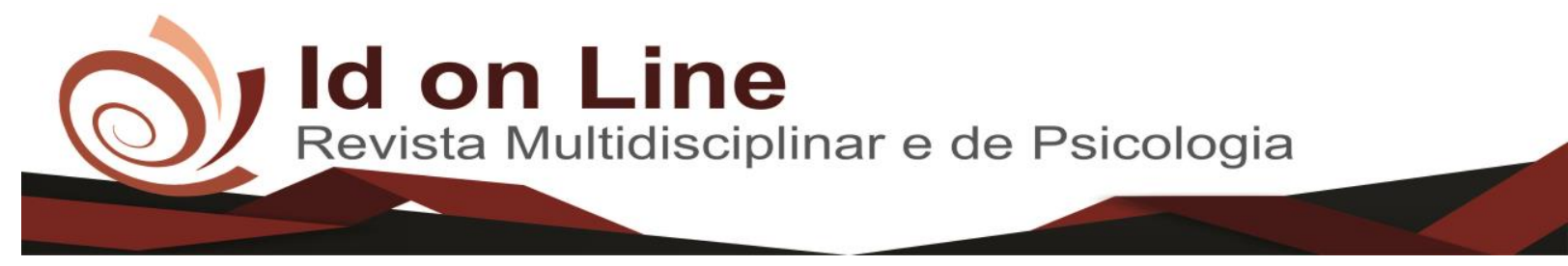

Artigo

\title{
Os Benefícios do Microempreendedor Individual
}

\author{
Maria Micaelle Bitu Primo ${ }^{1}$; Maria Erilúcia Cruz Macedo ${ }^{2}$
}

\begin{abstract}
Resumo: O empreendedor individual é uma pessoa que tem o seu próprio negócio, conhecido como pequeno empresário, passando a ter o registro no cadastro nacional da pessoa jurídica (CNPJ), possibilitando com facilidade a emissão de nota fiscal, abertura de contas bancarias e créditos e além dos benefícios com a previdência social, auxilio de doenças, salario maternidade, aposentadoria por invalidez. O pequeno empresário está obrigado a transmitir a declaração anual com a sua receita bruta até 81 mil reais e se tiver empregado informar o FGTS (Fundo de Garantia do Tempo de Serviço) e INSS (Instituto Nacional do Seguro Social) do empregado. Objetivo geral do presente trabalho é estudar e verificar as normas legais e os procedimentos essenciais para se tornar um empreendedor individual e demostrar os benefícios adquiridos através de sua legislação. Em seus objetivos específicos procura-se evidenciar a importância do processo de legislação do MEI, demostrar os procedimentos para se considerar o empreendedor individual e por fim, apresentar as obrigações do MEI. A construção do presente trabalho deu-se através da pesquisa bibliográfica em livros, artigos publicados e sites confiáveis relacionada ao assunto, de cunho descritiva e de característica qualitativa. Conclui-se que com a criação da lei complementar 128/08 os MEIs poderão ter o seu próprio negócio de forma regular.
\end{abstract}

Palavras-chave: Empreendedor individual. Benefícios. Pequeno empresário.

\section{The Benefits of the Individual Microentrepreneur}

\begin{abstract}
The individual entrepreneur is a person who has his or her own business, known as a small business owner, and has the registration in the national registry of the legal entity (CNPJ), making it easy to issue invoices, opening bank accounts and credits and beyond of benefits with social security, sickness benefits, maternity wages, disability pensions. The small business owner is required to transmit the annual statement with his gross income up to 81,000 reais and if he has employed inform the employee's FGTS and INSS (National Institute of Social Security). A general objective of this paper is to study and verify the legal norms and procedures essential to becoming an individual entrepreneur and to demonstrate the benefits acquired through its legislation. Its specific objectives are to highlight the importance of the MEI legislation process, to demonstrate the procedures for considering the individual entrepreneur and, finally, to present MEI obligations. The construction of the present work was done through the bibliographic research in books, published articles and reliable sites related to the subject, of descriptive character and qualitative characteristic. It is concluded that with the creation of complementary law 128/08, the MEIs may have their own business on a regular basis.
\end{abstract}

Keywords: individual entrepreneur. Benefits. Little businessman.

\footnotetext{
${ }^{1}$ Concludente do Curso de Ciências Contábeis da Universidade Leão Sampaio, em Juazeiro do Norte - CE.

E-mail: micaelleprimo@ hotmail.com

2 Professora Mestranda em Gestão. Faculdade Leão Sampaio. E-mail: erilucia@leaosampaio.edu.br
} 


\section{Introdução}

O empreendedorismo pode ser definido como o ato de empreendedor de novas possibilidades, visualizando oportunidades de negócio e buscando a plena realização das mesmas. Existem diversos indivíduos que são inegavelmente empreendedores, e estes geralmente se arriscam em atividades empresariais, muitas vezes, sem sucesso e outras vezes, com pleno sucesso (CHIAVENATO, 2012).

Empreendedor individual é a pessoa que trabalha por conta própria, tem registro de pequeno empresário e exerce uma das mais de 400 modalidades, tenha um faturamento limitado até $81.000,00$ por ano, não participe como sócio ou titular de outra empresa e contrate um empregado, pagando-lhe o salário mínimo ou o piso de sua categoria (PORTAL DO EMPREENDEDOR, 2018).

As vantagens para o empreendedor individual são: adquirir um registro na junta comercial, contribuir com a previdência social, crédito fácil nos bancos, emissão de nota fiscal ao consumidor final, isenção de imposto, simplificação de escrituração contábil e participação de licitações. Frente a esse contexto, apresenta-se a seguinte questão da pesquisa: Como se tornar um empreendedor individual?

Este trabalho tem como objetivo geral verificar as normas legais e os procedimentos essenciais para se tornar um empreendedor individual e demonstrar os benefícios adquiridos através de sua legislação. Em seus objetivos específicos, procura-se evidenciar a importância do processo de legislação do MEI, demostrar os procedimentos para se considerar o empreendedor individual e, por fim, apresentar as obrigações do MEI.

A relevância dessa pesquisa é mostrar os benefícios e obrigações do empreendedor individual, de acordo com o cenário atual brasileiro. Para que o assunto seja bem discutido, ainda são necessárias muitas pesquisas nessa área, haja vista dizer de poucas elaborações cientificas que falam sobre o assunto.

O presente trabalho foi desenvolvido através da pesquisa bibliográfica, usando livros, artigos publicados, relacionados ao assunto e sites confiáveis, de cunho descritivo e de característica qualitativa. 


\section{Empreendedorismo}

De acordo com Dornelas (2008), o empreendedorismo refere-se ao envolvimento de pessoas em processos pela busca de oportunidade de comercialização, a partir da inovação e criação de valores. Os empreendedores são pessoas que fazem o seu diferencial para serem reconhecidos.

Já para Chiavenato (2005, p. 3) diz que “o empreendedor é a pessoa que inicia ou opera um negócio para realizar uma ideia ou projeto pessoal, assumindo risco e responsabilidade e inovando continuidade". O empreendedor faz-se um investimento ao seu negócio para realizar suas atividades no mercado competitivo. O empreendedor é uma pessoa que trabalha por conta própria, que toma a iniciativa para o seu negócio crescer e sempre está criando inovações e realizações aos seus clientes para garantir o seu sucesso, e o empreendedor atribui-se os riscos financeiros, sociais e emocionais. (FERREIRA, SANTOS, SERRA, 2010).

Na visão de Chiavenato (2012), os empreendedores não são fornecedores de mercadoria ou serviços, eles são os heróis no mundo dos negócios, oferecem emprego à população, ingressam inovações e estimulam o crescimento da economia e atendem os clientes da melhor forma possível. Nos estudos do pesquisador Dornelas (2015), foi identificado que as principais caraterísticas dos empreendedores de sucesso são elas: visionários, pessoas que sabem tomar decisões, planejam, possuem conhecimento e fazem a diferença, sabem explorar, ao máximo, as oportunidades. São determinados e dinâmicos, dedicados, otimistas e apaixonados pelo que fazem, independentes e constroem seu próprio destino, ricos, líderes e formadores de equipes. As três caraterísticas básicas do espirito do empreendedor são apresentadas na figura 01, a seguir:

\section{Figura 01 - Características do Empreendedor}

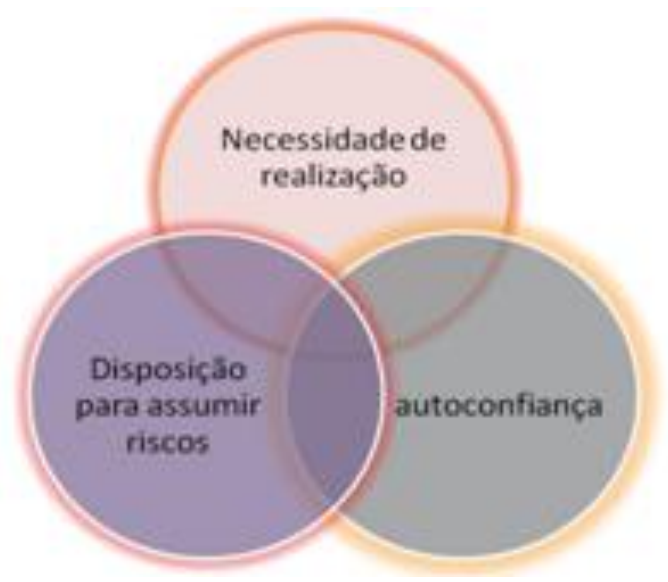

Fonte: Chiavenato, 2012 
Compreendendo melhor essa classificação do autor supracitado, deve-se saber:

1. Necessidade de realização: varia de pessoa para pessoa, necessita de realização que se contenta com o status atual, de alta necessidade, e que gosta de competir como padrão de perfeição.

2. Disposição para assumir riscos: os empreendedores, após os investimentos do seu negócio se iniciam com vários riscos, sendo eles: financeiro, psicológico, familiar.

3. Autoconfiança: abrange a capacidade do empreendedor que possa enfrentar os seus riscos, havendo o domínio ao seu redor (CHIAVENATO, 2012).

\section{Empreendedor Individual}

O empreendedor individual foi discutido na agência governamental, não só nos dias atuais, pois começou desde a Constituição de 1988, com as empresas de pequeno porte, que são presenteadas com o tratamento jurídico diferenciado, no surgimento de novos empreendimentos (ALENCAR SOBRINHO, 2013).

Com o surgimento da lei complementar $\mathrm{n}^{\circ} 123 / 06$, as empresas contempladas como microempresas e empresas de pequeno porte optantes pelo Simples Nacional, tiveram uma série de benefícios. Com isso, encontrava-se diversas dificuldades para o registro de autônomos, os empresários viam uma série de burocracia e gastos na abertura de suas entidades.

Observando essa situação, foi aprovada pelo Congresso Nacional a lei complementar $\mathrm{n}^{\circ}$ 128/08, e o presidente Luiz Inácio Lula da Silva a sancionou. Com isso, a lei apresentou grandes oportunidades de normalização das pessoas físicas que fazem a empresa, de forma autônoma (ALENCAR SOBRINHO, 2013).

Com a criação dessa lei, no ano seguinte, para Oliveira (2011), foi possível acessar o portal do empreendedor, onde os interessados conseguem o seu registro na junta comercial e na previdência social. Todos os métodos para esse registro são efetuados na internet de forma gratuita sem burocracia, no máximo com uma duração de 30 minutos. Ao final desse procedimento, o empreendedor individual imprimirá o comprovante do CNPJ e INSS, em que deverá ser assinado e enviado para a junta comercial junto com uma cópia do RG (Registro Geral). 
As pessoas interessadas podem procurar o SEBRAE (Serviço Brasileiro de Apoio às Micro e Pequena Empresa) ou profissional contábil mais próximo.

De acordo com o portal do empreendedor (2018), para o empreendedor se enquadrar no MEI, vale-se do comercio, indústria ou serviços. É necessário que haja alguns requisitos como ter um faturamento anual igual ou inferior a $81.000,00$, ter uma idade igual ou maior do que 18 anos, não possuir outro estabelecimento, ou participar de outra empresa como sócio ou titular, não prestar atividades de construção de edifício, execução de projetos como decoração de interiores, serviços de natureza intelectual regulamentados por lei, por exemplo, consultório odontológico, médico, fisioterapia, psicologia, escritório de contabilidade, advocacia.

Ainda de acordo com o portal acima citado, o empreendedor tem mais de 400 atividades disponíveis como açougueiro; Abatedor de aves, bovino e suíno; Artesão de bijuterias; Baleiro; Britador; Cantor musical; Carroceiro; Chaveiro; Churrasqueiro; Comerciante de Artigos de Relojoaria; Cozinheiro; Filmador, Fotógrafo; Maquiador; Mecânico; Moto taxista, Pintor; Pipoqueiro; Relojoeiro; Sorveteiro; Vendedor Ambulante de Produtos Alimentícios e entre outros.

Com essas atividades, os empreendedores individuais tiveram a oportunidade de construir o seu próprio negócio de forma legalizado. Com isso, facilitando a possibilidade desses interessados participar de licitações nos órgãos públicos.

Sobre o recolhimento do empreendedor, o Comitê Gestor receberá um recolhimento fixo mensal, de no mínimo $\mathrm{R} \$ 48,70$ (quarenta e oito reais e setenta centavos) dependendo do CNAE (Código Nacional de Atividade Econômicas) a título de contribuição para a seguridade social, 1,00 (um real) a título de ICMS (imposto sobre circulação de mercadorias e serviços) e 5,00 (cinco reais) a título de ISS (imposto sobre serviços), para as empresas de serviços (PORTAL DO EMPREENDEDOR INDIVIDUAL, 2018).

Conforme a lei no 128/08, o MEI está dispensado do imposto de pessoa jurídica (IRPJ), contribuição sobre o lucro líquido (CSLL), programa de integração social (PIS), contribuição para o financiamento da seguridade social (COFINS) e imposto sobre produtos industrializados (IPI) (BRASIL, 2018).

O empreendedor individual tem a obrigatoriedade de informar a Declaração Anual do Simples Nacional - DASN-SIMEI, tendo como o último dia útil do mês de maio. Nessa declaração, informamos a receita bruta do ano anterior, a contratação do empregado, quando houver (SIMPLES NACIONAL, 2018).

O DASN-Simei, o governo criou esse sistema para facilitar os empreendedores efetuarem a declaração anual. Para registrar essa declaração, é preciso dos seguintes passos: 
acessar a página DASN-Simei, informar o número do CNPJ, comunicar o ano anterior, depois informa a receita bruta anual e transmitir essa declaração e imprimir (SIMPLES NACIONAL, 2018).

Conforme o Portal do empreendedor (2018), quando o MEI entrega a declaração anual do simples nacional do MEI (DASN-Simei), atrasada, ficará sujeito ao pagamento de uma multa, no valor mínimo de 50,00 (cinquenta) reais ou 2\% (dois) por cento referente ao anocalendário.

O empreendedor pode admitir um funcionário com remuneração até um salário mínimo ou piso de categoria a que pertencer, e terá garantias prevista na lei. O MEI deve recolher mensalmente 8\% de FGTS (Fundo de Garantia por Tempo de Serviços) e contribuir 109,94 de GPS (Guia da Previdência Social), que corresponde a 11\% do salário mínimo, sendo 28,62 que valem 3\% do salário mínimo para a previdência. Com isso, o empregado contribui com $8 \%$ do seu salário e terá todos os seus benefícios da previdência social como: aposentadoria, seguro desemprego, auxilio de doença ou acidente de trabalho, licença maternidade (PORTAL EMPREENDEDOR, 2018).

O MEI com a alíquota da contribuição previdenciária tem o direito de aposentadoria por idade, para as mulheres são 60 anos e para os homens 65 anos, mas para ter esse direito reconhecido, é necessário ter uma contribuição durante 15 anos. No caso, a aposentaria seja por invalidez no caso de acidente no trabalho não existe prazo (CENTRAL DO MEI, 2016).

O empreendedor com essa contribuição tem o direito de aposentar-se com o valor de um salário mínimo. Será superior, quando o MEI realizar em outras atividades e contribuir com a previdência as duas atividades. Nessa situação, o tempo das duas contribuições será somada para a autorização do benefício.

No ano de 2015, mudou a pontuação de contribuição. Segundo o Sebrae, essa aposentadoria por tempo de contribuição soma-se a idade e o tempo de contribuição para concluir 85 pontos para as mulheres e 95 pontos para os homens. Essa faixa conforme muda de acordo com a expectativa de vida dos brasileiros (SEBRAE, 2018).

\section{Contabilidade no MEI}

O empreendedor individual estará desobrigado a transmitir as escriturações contábeis, bem como não é necessário manter os livros em registro. Portanto, o empregador deve ter um controle de entrada e saída, aplicar uma planilha de fluxo de caixa para que haja um controle 
de quanto estão ganhando para informar a sua receita total a cada ano com os seus relatórios mensais (PORTAL DO EMPREENDEDOR, 2018).

Para o mesmo site mostrado acima, os relatórios serão enviados até o dia 20 de cada mês relacionada à sua receita obtida anteriormente, por exemplo o MEI deve fazer o seu relatório no mês de setembro relacionado ao mês de agosto. Os modelos desse relatório estão disponíveis no site http://www.portaldoempreendedor.gov.br. Essa organização lhe dá subsidio de informações para que o próximo ano possa declarar o seu faturamento junto ao físico.

Para transmitir o relatório anual, é bem simples, os procedimentos são: entrar no site do portal do empreendedor, DASN-SIMEI, informar o número completo do CNPJ, digitar os caracteres do site, tipo de declaração, valor da receita bruta total (Comércio, Indústria e Serviços), empregado e transmitir (SIMPLES NACIONAL, 2018).

\section{Crédito Fácil}

Para a MEI, o banco do Brasil (2018) oferece uma facilidade para a sua abertura de conta corrente, empréstimo, financiamento e capital de giro. Disponibiliza um cartão de credito chamado Ourocard empreendedor. Esse cartão não apresenta anuidade, pagamento de compromissos, saques e depósito.

Já na Caixa econômica federal (2018), ao empreendedor individual é ofertado um empréstimo com a taxa diferenciada conhecida como microcrédito caixa, o limite desse empréstimo depende da análise de credito e da capacidade de pagamento do empreendimento, esse limite vai de 300,00 (trezentos) reais até 15.000,00 (quinze mil) reais, de acordo com a evolução do empreendimento. O prazo de pagamento é de 4 a 24 meses.

O empreendedor através do Banco do Nordeste (2018), consegue um empréstimo por meio de um programa chamado crediamigo, para melhorar a aplicação de recursos na sua entidade. Ao terminar a solicitação, é permitido o prazo de 7 dias úteis para a liberação do dinheiro na sua Conta corrente. Os valores iniciais variam de 100,00 (cem) até 4.000,00 (quatro mil) reais, conforme à sua necessidade e o ponto do negócio. 


\section{Alvará}

O empreendedor individual, após finalizar o cadastro no site do portal empreendedor, receberá o Certificado da condição do empreendedor individual (CCMEI). Nesse registro, estão compostos o seu CNPJ e as inscrições na junta comercial. Diante disso, o seu alvará de funcionamento está liberado, com isso está comprovado que a empresa está hábita a exercer sua atividade de formar regular (PORTAL DO EMPREENDEDOR, 2018).

O site Ser Contabilidade (2015) afirma que o alvará de funcionamento é um documento permitido pela Prefeitura, concedido à localização e ao funcionamento que possam funcionar de forma respeitada, ainda com as normas de funcionamento, zoneamento, edificadas, higiene sanitário, segurança pública e higiene do trabalho e meio ambiente.

Conforme o empreendedor individual (2018), a concessão do alvará de funcionamento deve ser realizada após 180 dias da formalização do empreendedor individual, a responsabilidade é da Prefeitura, com observância das normas contidas nos códigos de zoneamento urbano e de posturas municipais.

Ainda no site do empreendedor, o MEI poderá ter o seu funcionamento na sua própria residência, desde que o empreendedor individual obedeça às normas municipais e com a resolução no 16/2006 do CGSIM - Comitê para Gestão da Rede Nacional para Simplificação do Registro e da Legalização de Empresas e Negócios. Após a emissão do alvará ou licença de autorizações de funcionamento, a Prefeitura ou órgão do estado poderão realizar a vistoria no estabelecimento quando houver o um risco muito alto durante a sua atividade.

Já para o Sebrae (2018), o MEI que exerce suas atividades na própria residência terá um tratamento favorecido em relação à tributação municipal. Por conta disso, as prefeituras aplicarão a tributação de menor alíquota vigente no local, sem que o órgão esteja no prejuízo de eventual.

\section{Benefícios no MEI}

Após a formalização do MEI, o empreendedor individual passa a contar com algumas vantagens como: contribuição com a previdenciários e emissão de nota fiscal avulsa.

Benefícios previdenciários, a partir de 12 (doze) meses de contribuição ao INSS, o empreendedor tem o direito do auxílio doença e aposentadoria por invalidez, lembrando-se que esses benefícios são nos casos de acidente de qualquer natureza ou doença prevista em lei. No 
caso de salário maternidade são fundamentais 10 (dez) meses de contribuição. Pensão por morte para os dependentes, é preciso que o empreendedor tenha efetuado 18 (dezoito) meses de contribuições previdenciárias (PORTAL DO EMPREENDEDOR, 2018).

Emissão de nota fiscal - o MEI não é obrigado a emitir nota fiscal ao consumidor final, mesmo que a venda seja de um estado para outro, mas pode emitir se desejar. As notas fiscais podem ser eletrônicas ou avulsas. No caso de nota fiscal eletrônica, o MEI deve solicitar à Secretaria da Fazendo do seu estado.

Esses procedimentos variam de estado para estado. Na emissão dessa nota, o empreendedor pagará a mesma quantidade das empresas de pequeno porte. Já para a emissão de nota fiscal avulsa, conhecida como nota fiscal comum, os procedimentos são bem mais fáceis de emitir, podendo emitir e consultar no site da SEFAZ (PORTAL MEI EMPREENDEDOR, 2018).

\section{Metodologia}

Segundo Pereira (2016, p. 43) “A metodologia é o conjunto dos métodos que cada ciência particular põe em ação. A colaboração entre demonstração lógica e experimentação, a interação, entre ciência pura e tecnologia, é uma característica do espírito científico contemporâneo".

O presente trabalho foi elaborado usando como metodologia a pesquisa bibliográfica, de cunho descritiva e abordagem qualitativa. Utilizaram-se os principais autores e site para o desenvolvimento desse trabalho.

Esse trabalho teve como base para realizar essa pesquisa - livros da biblioteca do Centro Universitário Doutor Leão Sampaio, artigos relacionados ao assunto, leis, sites confiáveis e livros disponíveis na biblioteca virtual dessa Universidade, com a finalidade de demonstrar a relevância do empreendedor individual.

De acordo com Gil (2007), a pesquisa bibliográfica é realizada através de documentos já elaborados e publicados na internet e essa pesquisa é encontrada, principalmente nos livros e artigos científicos.

Segundo Pereira (2016, p.89):

Diz que a pesquisa qualitativa não se preocupa com representatividade numérica, mas sim, com o aprofundamento da compreensão de um grupo social e de uma organização. Os pesquisadores que adotam a abordagem qualitativa se opõem ao pressuposto que defende um modelo único de pesquisa para todas as ciências, já que as ciências sociais têm sua especificidade, o que pressupõe uma metodologia própria. 
As pesquisas descritivas, na visão de Gil (2007), são uma forma na qual se descreve determinadas características sobre um assunto, para que então se estude um grupo com o intuito de fornecer uma nova visão sobre o problema, assim como associação entre varáveis.

\section{Considerações Finais}

A proposta dessa pesquisa foi de compreender os benefícios e obrigações de forma ampla, de modo a contextualizá-la sempre dentro cenário histórico atual de constantes mudanças e configurações. O MEI foi introduzido pela Lei Complementar 128/08 e inserido na Lei Geral da Micro e Pequena Empresa (Lei Complementar 123/06), que possibilita a formalização de empreendedores por conta própria.

O empreendedor Individual foi criado para que os trabalhadores informais estejam dentro da Legalidade e principalmente para provar que o trabalho formal é muito mais rentável do que trabalho informal.

Essa pesquisa tem como objetivo analisar e mostrar a importância dos benefícios e obrigações do empreendedor individual, os benefícios mais amplos significam a forma de pagamento da carga tributária, ter um funcionário contratado que receba o salário mínimo ou o piso da categoria, contribuição com a previdência e a obrigação mais abrangente para o empreendedor e a emissão do DASN-SIMEI a cada ano.

O MEI trabalha por conta própria e se legaliza como pequeno empresário, desde que fature no máximo 81 (oitenta e um) mil reais por ano, sendo dividido por mês o valor de R \$ 6.750,00 (seis mil setecentos e cinquenta reais), e que não tenha participação em outra empresa como sócio ou titular.

A contribuição do MEI veio dá necessidade do fisco de angariar recursos e formalizar os trabalhadores que exerciam sua profissão sem gerar nenhuma espécie de benefício para o estado. Pensando nisso, o MEI obteve vantagens em comparação com as outras formas de regimes existentes. Uma dela é a emissão de notas fiscais eletrônicas ao consumidor final, registro na junta comercial e cadastro no CNPJ.

Para se tornar um empreendedor individual, basta acessar o site do portal do empreendedor, preencher as informações necessárias, como dados pessoas, informações financeiras e atividades que irá exercer.

Atualmente, o número de formalizados na categoria do MEI já ultrapassa a marca de 7 milhões de empreendedores. No entanto, está longe de se chegar ao ponto de legalizar todos os 
empreendedores informais. Com isso, o governo precisa criar uma forma para que haja uma fiscalização maior para que o número de informalidade possa diminuir no Brasil.

\section{Referências}

BANCO DO BRASIL. Disponível < https://www.bb.com.br/portalbb/page3,19279,19281, 21,0,1,1.bb > acesso em 22 set. 2018.

BANCO DO NODESTE. Disponível < https://www.bnb.gov.br/ > acesso em 22 set. 2018.

BRASIL. Lei complementar $n^{\circ}$ 123/06, 14 de dezembro de 2006. Institui o Estatuto Nacional da Microempresa e da Empresa de Pequeno Porte; altera dispositivos das Leis no8.212 e 8.213, ambas de 24 de julho de 1991, da Consolidação das Leis do Trabalho - CLT, aprovada pelo Decreto-Lei ${ }^{0} 5.452$, de $1^{\circ}$ de maio de 1943, da Lei ${ }^{\circ} 10.189$, de 14 de fevereiro de 2001, da Lei Complementar $\mathrm{n}^{0}$ 63, de 11 de janeiro de 1990; e revoga as Leis $\mathrm{n}^{\circ}$ 9.317, de 5 de dezembro de 1996, e 9.841, de 5 de outubro de 1999. Disponível em < http://www.planalto.gov.br/ccivil_03/LEIS/LCP/Lcp123.htm > acesso em: 29 ago. 2018.

Lei complementar $\mathbf{n}^{\mathbf{0}} \mathbf{1 2 8 / 0 8 , 1 9}$ de dezembro de 2008. Altera a Lei Complementar no 123, de 14 de dezembro de 2006, altera as Leis nos 8.212, de 24 de julho de 1991, 8.213, de 24 de julho de 1991, 10.406, de 10 de janeiro de 2002 - Código Civil, 8.029, de 12 de abril de 1990, e dá outras providências. Disponível em $<$ http://www.planalto.gov.br /ccivil_03/leis/LCP/Lcp128.htm > acesso em 04 set. 2018.

CAIXA ECONOMICA FEDERAL. Disponível < http://www.caixa.gov.br/empresa/creditofinanciamento/crescer/Paginas/default.aspx > acesso em 21 set. 2018.

CENTRAL DO MEI (2016). Disponível < https://centraldomei.com/mei-como-funciona-aprevidencia-social/ > acesso em 15 set. 2018.

CHIAVENATO, Idalberto Empreendedorismo: dando asas ao espirito empreendedor. 4. Ed. - Barueri, SP: Manole, 2012.

CONTABILIZEI. Disponível em < https://www.contabilizei.com.br/contabilidadeonline/atividades-mei-tabela/ > acesso em 01 set. 2018.

DORNELAS, José Carlos Assis, 1971. Empreendedorismo: transformando ideias em negócios - 3.ed. - Rio de Janeiro; Elsevier, 2008. - $3^{\text {a }}$ reimpressão.

. Empreendedorismo na Prática: Mitos e Verdades do empreendedor de sucesso - 3.ed. - Rio de Janeiro: LTC, 2015. Disponível em < https://dliportal.zbra.com. br/Login.aspx?key=leaosampaio > acesso em: 08 ago. 2018.

FERREIRA, Manuel Portugal, SANTOS, Joao Carvalho, SERRA, Fernando A. Ribeiro Ser Empreendedor: Pensar, Criar e Moldar a nova empresa - São Paulo: Saraiva, 2010.

GIL, Antônio Carlos Métodos e técnicas de pesquisa social - 5. Ed. - são Paulo; atlas, 2007. 
MATIAS, José Pereira. Manual de metodologia da pesquisa científica - 4. ed. - São Paulo: Atlas, 2016. Disponível em < https://integrada.minhabiblioteca.com.br > acesso em: 10 out. 2018.

OLIVEIRA, Rikaline Patrício. Microempreendedor Individual: Formalização e inclusão social. Disponível na biblioteca da universidade Leão Sampaio acesso em: 10 ago. 2018.

PORTAL DO EMPREENDEDOR. Disponível em < http://www.portaldoempreendedor. gov.br/ > acesso em: 31 ago. 2018.

SEBRAE. Disponível < http://www.sebrae.com.br/sites/PortalSebrae/faq/quais-os-beneficiosprevidenciarios-do-mei,04ebd7d718a04510VgnVCM1000004c00210aRCRD > acesso em 16/set/2018.

SER CONTABILIDADE. Disponível < http://sercontabilidade.com.br/blog-abertura-deempresa-alvara-de-funcionamento.htm > acesso em 20 set. 2018.

SIMPLES NACIONAL. Disponível <http://www8.receita.fazenda.gov.br/Simples Nacional/Arquivos/manual/PerguntaoMEI.pdf > acesso em 11 set. 2018.

SOBRINHO, Hérbio de Matos Alencar. A Percepção das pessoas regularizadas enquanto empreendedoras individuais - EIs sobre o Programa EI. Disponível na biblioteca Universidade Leão Sampaio > Acesso em 20 ago. 2018.

\section{Como citar este artigo (Formato ABNT):}

PRIMO, Maria Micaelle Bitu; MACÊDO, Maria Erilúcia Cruz. Os Benefícios do Microempreendedor Individual. Id on Line Rev.Mult. Psic., 2019, vol.13, n.43, p. 102-113. ISSN: 1981-1179.

Recebido: 15/11/2018;

Aceito: 19/11/2018 